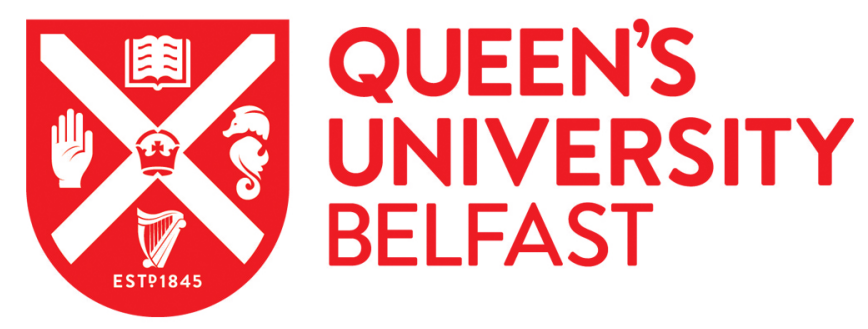

\title{
Finding Your Feet in the Field: Critical Reflections of Early Career Researchers on Field Research in Transitional Societies
}

Browne, B., \& Moffett, L. (2014). Finding Your Feet in the Field: Critical Reflections of Early Career Researchers on Field Research in Transitional Societies. Journal of Human Rights Practice, 6(2), 223-237.

https://doi.org/10.1093/jhuman/huu010

Published in:

Journal of Human Rights Practice

Document Version:

Peer reviewed version

Queen's University Belfast - Research Portal:

Link to publication record in Queen's University Belfast Research Portal

Publisher rights
Copyright The Author (2014). Published by Oxford University Press. All rights reserved.

This is a pre-copyedited, author-produced PDF of an article accepted for publication in Journal of Human Rights Practice following peer review. The version of record, Browne, B \& Moffett, L 2014, 'Finding Your Feet in the Field: Critical Reflections of Early Career Researchers on Field Research in Transitional Societies' Journal of Human Rights Practice, vol 6, no. 2, pp. 223-237, is available online at: http://jhrp.oxfordjournals.org/content/6/2/223

General rights

Copyright for the publications made accessible via the Queen's University Belfast Research Portal is retained by the author(s) and / or other copyright owners and it is a condition of accessing these publications that users recognise and abide by the legal requirements associated with these rights.

Take down policy

The Research Portal is Queen's institutional repository that provides access to Queen's research output. Every effort has been made to ensure that content in the Research Portal does not infringe any person's rights, or applicable UK laws. If you discover content in the Research Portal that you believe breaches copyright or violates any law, please contact openaccess@qub.ac.uk. 


\section{Article Title: Finding your feet in the field: critical reflections of early career researchers on field research in transitional societies}

Dr Brendan Browne* and Dr Luke Moffett**

Manuscript type: Policy and Practice Notes/Article, Journal of Human Rights Practice

* Research fellow, School of Law, Queen's University Belfast. Funding for Dr Browne's research is gratefully acknowledged from the Department for Employment and Learning Doctoral Scholarship, Northern Ireland. Further financial support for this research was kindly provided by the Sir Robert Hart Fund, Queen's University Belfast; The Council for British Research in the Levant (Small Travel Grant); and the School of Sociology, Social Policy \& Social Work, Internationalisation Fund, Queen's University Belfast. Email:

bbrowne02@qub.ac.uk

** Lecturer, School of Law, Queen's University Belfast. Dr Moffett's research was kindly supported by the County Antrim Grand Jury Bursary fund. Email: 1.moffett@qub.ac.uk

Key Words: fieldwork; ethics; conflict; research preparation; reflexivity 


\section{Finding your feet in the field: critical reflections of early career researchers on field research in transitional societies}

\section{Introduction}

In echoing the views of others who have conducted research in some of the world's most challenging and volatile regions, 'All too often researchers are left to their own innate sensibilities, talents, and skills to identify and resolve a range of ethical, social, and political challenges that inevitably arise in the field.'(King, 2009: 8). Whilst in this paper we err on the side of caution in suggesting that the experiences shared in the following discussion, including decisions made in advance of and whilst engaged in the field, are anything other than personal reflections; we share them in good faith in an attempt to counteract what we believe is a lack of transparency that accompanies fieldwork, particularly that which takes place in conflict or transitional settings. As the demand to undertake research in conflict and transitional regions exponentially increases, (a fetishism for conflict research that brings with it problems of its own making, many of which are beyond the scope of this paper) so too has there emerged research methodology literature which focuses on the challenges associated with working in these politically volatile regions (Sluka, 1990; Nordstrom and Robbenm 1995; and Kovats-Bernat, 2002). Despite this literature, there remains reluctance on behalf of fieldworkers to be candid and open in sharing their personal experiences on the challenges faced for fear of academic critique or scholarly reprisal.

As has been suggested on a number of occasions, the one thing which is certain about fieldwork is its uncertainty (Burgess, 1982). Irrespective of the rigorous preparations made in advance of entering the field, adaptability and the capacity to think on your feet remain key attributes which researchers must learn to master at an early stage. With little advance warning, unforeseen situations arise, particularly given the fluid nature of fieldwork that takes place in a conflict or transitional setting, which require researchers to re-evaluate their research strategy, or at worst their presence in the field itself. Although neither author was forced to depart the field as a result of the deteriorating conflict environment, both make reference to the importance of timing when planning the prolonged trips for data collection and reflect on strategies for exiting the field in the event that such a situation becomes reality.

That said, steps taken in advance greatly enhanced the ability of both authors to adapt upon arrival in their respective fieldwork destinations. Whilst not propagating a checklist of do's and don'ts, we provide examples of scenarios faced and how we managed to overcome these, at times, complex and challenging situations. Beginning first with Moffett's reflections on conducting fieldwork in East Africa before turning to the experiences of Browne in Palestine, the authors consider two central aspects of their fieldwork experiences, namely: the planning made in advance of entering the field; and the challenges faced whilst in the field. In terms of planning, the focus is on the practical steps taken to ensure smooth transition from behind the office desk to entering the field itself, the ethical 
considerations of the work, the timing of the visit, and the limits to proper advance planning with a focus on the lack of training provided at a university level. When considering the challenges faced in the field itself both authors reflect upon difficulties related to physical access, the emerging ethical predicaments (including ensuring researcher legitimacy, data security, and researcher safety), and the difficulties associated with living in demanding and unfamiliar settings. Notwithstanding the fact that proper planning and preparation can help to mitigate against unwelcome fieldwork experiences, the paper ultimately draws the conclusion that success during fieldwork is largely based upon rather unscientific and unsatisfactory subjective attributes of perseverance, personality, and luck.

\section{A. Researching in East Africa: Experiences from the field}

The following discussion is based on field experience gained as part of a doctoral course, which investigated the extent to which victims' interests are considered in international criminal tribunals in light of international human rights law. My field experience began when I first travelled to East Africa in 2009, a few months before commencing my doctoral course to gain insight into working with victims of mass atrocities in Uganda, Rwanda and eastern Democratic Republic of Congo (DRC). I organised an internship with a Rwandan NGO, which provided assistance to survivors of the Rwandan Genocide and to internally displaced communities in eastern DRC, to smooth my transition into the field and to see whether I could cope with working in such an environment on victims' issues. After nearly three months this experience proved invaluable in helping to improve my confidence in working in the field, as well as building up important contacts for future research, an experience shared by Wamai (this volume). In 2011 I returned to East Africa to carry out my $\mathrm{PhD}$ research in Northern Uganda and eastern DRC on the perspectives of stakeholders on the International Criminal Court involving interviews and focus groups.

\section{Considerations in advance of entering the field}

As with any type of research project, planning is key. Timing and ensuring that the research is well organised and ethical is vital, but in reality things at times can go awry. A key consideration before engaging in fieldwork is knowing when to go and when you are ready to go, in order to maximise your time and resources. In 2010 I had been awarded a travel bursary to conduct field research in East Africa, but was dissuaded from going by my partner and supervisor, who both thought it was not the right time to travel, as I had only conducted preliminary desktop research and would not be making the best use of my time. Reflecting on this period, while frustrating after going through the fundraising process, it was the correct decision. When I finally did leave for Kampala in June 2011, it was only after a long period spent at home preparing. I outlined a list of key local actors I should speak to by targeting governmental agencies, staff of the International Criminal Court, victim and human rights organisations, civil society leaders and ex-combatants. Planning to enter the field also included more practical aspects, such as getting the correct vaccinations and medication, arranging flights, insurance 
and internal transport, as well as organising accommodation in Northern Uganda. Nonetheless, although preparing to go out at a particular time is important, by chance local developments meant that I was able to attend the trial of Thomas Kwoyelo, the first Lord Resistance Army commander to be prosecuted, an invaluable experience which enriched my discussions with stakeholders and enabled me to provide some more relevant knowledge exchange to participants.

Coming from a law background I had no formal training in research methods, particularly in qualitative research. I was advised to consult some books in the area and undertake training available at the university on ethical research; despite this I felt quite unfamiliar with the more tacit knowledge of 'doing' field research. Nevertheless learning by doing, through setting up interviews with stakeholders and being prepared for them, was considered by many in may discipline to be the best way to understand this type of research (see Wamai, this volume). Importantly I was able to work informally with those who were approachable, patient and willing to give me advice on how to improve my future performance.

With regard to ethics, before entering the field it was necessary to gain ethical approval from my school. The proposed research fell into the high risk category due to its focus on victims. My ethics document outlined how I proposed to conduct my research, identified possible ethical issues which could arise, and included a consent form to explain my research to participants, which was presented to interviewees and focus groups members. This document was informed by my first year $\mathrm{PhD}$ assessment which afforded me the chance to discuss ethics with two faculty members, a useful opportunity to evaluate my approach in order to minimise the risks to interviewees, the university, and myself. In addition, interview questions were prepared in advance to guide the process and ensure that the most relevant and useful information could be gathered to answer the research questions set. While this preparation and organisation provided guidance before an interview, or a safety net if a question was forgotten, in practice such meetings generally flowed, allowing conversational discussions where the researcher and participants could flag up contemporary issues, rather than strict adherence to formal questioning.

\section{Specific challenges in the field}

\section{a) Physical access}

In terms of physical access, entering Uganda and Rwanda was relatively incident free given that, being born in Northern Ireland, I hold both Irish and British passports. This enabled me to switch my passports at the border to avail of free visas to both countries. However, my experience in DRC was less pleasant, on one occasion I was detained at a border crossing, had my passport and possessions taken, was placed in a small room and interrogated by a customs officer brandishing a rifle and demanding a bribe. While I said I was visiting friends, (as revealing we were working for an NGO would have resulted in a larger bribe), the situation could have deteriorated significantly had we not been travelling with a Rwandan colleague translating and mediating the situation. When trying to travel across into the DRC again in 
2011 I was barred from entry as I did not have the correct visa and was asked to hand over a substantial sum of money, which I could not afford, thus preventing me from entering the country. Unable to conduct research in the DRC, I returned to Uganda to carry out some further research. Although learning the hard way, an important lesson to take is that fieldwork does not always run smoothly or to plan. It is thus useful to have local contacts to mediate difficult situations and contingencies when plans fall through.

Other bureaucratic incidents experienced included attempting to gain interview consent in Northern Uganda, with some targeted respondents refusing consent to an interview unless I had a letter from my University signed by all five levels of the local administrative commissions, which took up time and effort. Whist this was at times frustrating, I soon appreciated that it connoted respect to local customs and laws. This document later proved invaluable in building trust and respect with community leaders and individuals, particularly amongst victims who were naturally suspicious of my presence in the field.

\section{b) Ethical and other practical considerations}

Field research in conflict/post-conflict societies gives rise to a number of ethical challenges. One of the biggest ethical issues is maintaining confidentiality to ensure that the information gathered is not discovered or used by a third party. With regard to ethics, it is always prudent to hold interviews and focus groups in private and out of view, as you do not know who is listening. If possible one should minimise your visibility in the field when arriving into politically sensitive areas until sufficient trust is built up and risks minimised. Individuals often told me that it was easy to spot international criminal investigators as they were often white and were transported in SUVs. It is also important to preserve confidentiality after the interview. Maintaining data security can cause an immense amount of stress on researchers (Wood, 2006: 384). When crossing the border and being searched a colleague left his backup hard drive in the public bus we were travelling on. Upon returning the hard drive was missing, luckily no research or sensitive material was on it. Nevertheless, this experience emphasises the importance of keeping data secure, ideally on your person at all times, encrypted and backed up online.

Managing a violent context and associated trauma is also an ethical challenge. During my time in the eastern DRC I experienced frequent scenes of overcrowded internally displaced person camps. Our presence in the camps was to document the, at times, harrowing testimonies of individuals who had survived a massacre while children nearby were dying from cholera. Understandably the experience in the DRC was traumatising, and two colleagues who had joined us in the field found it difficult to cope. This 'secondary' or 'vicarious' trauma has been noted by others (Wood, 2006: 384; McCann and Pearlman, 1990) when working with victims, survivors and witnesses of gross violations of human rights, due to the empathy with the individual's situation and suffering, which has a cumulative effect over time. In my experience I found it helpful to talk to friends, as well as taking a day or two each week to relax. While such situations are challenging, I am indebted to the victims and survivors who, 
despite the difficulties, spoke to me, and I hope that I can effectively convey their perspective through my forthcoming research (Moffett, 2014).

Ensuring one is sensitive to victims and survivors of traumatic experiences, which include not only direct victims, but their families and communities, is both best practice and a means of strengthening rapport. Having a consent form which explain in the participant's language the ultimate aims of the research is a good way to offer a protective framework for those taking part, and yourself, outlining that they do not have to answer any question, that the interview can be stopped at any time and that all references to them will be made anonymous, etc. In addition, it is good practice to ensure that a support person through a counsellor or community leader is available to hand to provide assistance to victims immediately after the interview. Ethical research requires that researcher do no further harm to such vulnerable individuals, and so careful consideration and respect is needed to gather information in delicate situations, such as those that arise in conflict and transition.

One practice I found useful was to keep a field diary to reflect on interviews. The diary enabled me to assess in terms of interview technique and lines of questioning, what worked and what did not, and to document more informal details which gave colour to interviews, such as the interview environment (one of which took place in a destroyed factory), as well as to note any ethical implications which arose, so as to inform future field research. The diary also allowed me to consider the impact of trauma on myself and identify appropriate coping mechanisms.

A further consideration is identifying an appropriate gatekeeper. In Northern Uganda I worked through a local victims' organisation who directed me to people I should speak to. In conducting my focus groups, I contacted community leaders and organised meetings. This led to community gatherings where I was introduced, asked to explain my research and questioned by different individuals. Attending such community gatherings helped to assuage any misgivings the community had about me and my research; although this took some time, it enabled trust to be built between the community and myself.

There are benefits in the researcher translating for themselves so as to better understand crosscultural meanings (Temple and Young, 2004: 168); however unfortunately I did not speak the local Acholi language. As I came to know the community leader I asked him to act as a translator. A professional translator could have translated, but the community leader was well educated and trusted within the community, he was also able to understand and explain the nuanced answers of participants and their backgrounds. However, using translators in field research, particularly when the topic is of a sensitive nature, remains a moot issue. Some translators can shape answers to confirm to their own views, or translate information in a manner they believe the researcher may want to hear (Jacobsen and Landau, 2003: 9). In addition, introducing another outsider (perhaps someone from a different ethnic group) can lead to distrust and unwillingness on behalf of participants to share information (Pittway et al, 2010: 236). Insider translators can also bring their own baggage through their personal knowledge of the respondent, or they could be put at risk once the researcher has left the field (Berman and Tyyskä, 
2010). Appreciating these limitations, having a trusted translator, recognised by the researcher and research participants, is vital.

Perhaps one of the most disconcerting challenges I faced when working with the victimised communities was their frustration in engaging with researchers. Many individuals and communities had hosted a number of investigators and researchers before me, with none returning to the field to inform the communities of their research findings or its impact. As with Browne's and Wamai's (this volume) field research, issues of reciprocity, knowledge exchange, and the long term impact of participants' engagement with researcher after the research, play an important part in researcher legitimacy, sustainability and respect for vulnerable individuals and the community, which requires further reflection by researchers before entering the field (discussed in greater detail below).

\section{B. Researching in Palestine: Experiences from the field}

The experiences shared here stem from two broken years of fieldwork in the Occupied Palestinian Territories (hereinafter Palestine). The fieldwork involved collecting a range of qualitative data for presentation in my doctoral thesis. The focus of the research was to gain a deeper understanding on the role which commemorations assume in conflicted or divided societies and involved meeting with a range of stakeholders including: senior members of the Palestinian Liberation Organisation, Palestinian non-governmental organisations, community-based organisations working in the West Bank, and refugee camp officials living in Palestine. Given that the fieldwork setting is an area famed for its instability and volatility, unsurprisingly there were a wide range of issues which required careful consideration in advance of entering the region itself. A number of the challenges I envisaged were mitigated with meticulous advance planning and preparation including: the removal of the initial culture shock through embarking on preliminary fieldtrips; establishment of a link with local community based organisations in the region; and liaison with research institutions in East Jerusalem, in particular the British Academy sponsored Kenyon Institute (my chosen area of residence). However, a range of difficulties surfaced whilst in the field, perhaps unsurprisingly given that the period of time set aside for fieldwork coincided with a particularly tumultuous moment in recent Middle Eastern history; the Arab Spring Uprisings. As such, the conclusions I draw upon during personal reflection are that advance preparations can only account for so much when engaging in fieldwork in highly fluid and ever changing conflict environments.

\section{Considerations in advance of entering the field}

The requirement to ensure fieldwork adheres to a certain ethical standard is a consideration any researcher must be aware of when designing their research project. Unquestionably when the work takes place in a live conflict zone, such as is the case in Palestine, specific ethical issues including researcher and participant safety, data security and confidentiality, and informed consent assume greater significance. Being acutely aware of my position as an outsider in the research setting, the issue of informed consent was one that required robust defence when seeking ethics approval from my school's 
ethical review panel. After gauging the experiences of others who had worked in similar settings, I drafted an A4 page outlining in Arabic and Hebrew my reasons for being in the field (Romano, 2006) ensuring this explanatory sheet was on my person at all times. This served the purpose of not only alleviating suspicions attached to my presence in the field, but when produced at the beginning of an interview, satisfied the need to gain informed consent from those taking part in the study.

Similarly, in advance of entering the field I registered with an online data storage service that would allow me to upload audio recordings and typed transcripts of interviews conducted in the West Bank before returning to my base in East Jerusalem via the Israeli controlled Qalandia checkpoint. This relatively straightforward step had greater significance than previously expected in that it aided in the generation of trust between researcher and participant, many of whom expressed concern that information shared during the interview exchange would be seized by Israeli Border Guards or 'other' officials whilst crossing one of many military checkpoints. Not only did such a move ensure I was able to return to Belfast without having suffered the ignominy of having lost data I had worked hard to gather, ${ }^{1}$ more importantly the steps taken increased the safety of my research participants, the majority of whom live in constant fear of Israeli surveillance and arrest.

Other challenges I experienced in advance of my period of fieldwork included multiple failed attempts to make electronic or written contact with potential research respondents in order to arrange meetings and interviews in advance of flying to Palestine. The reasons for targeted respondents in Palestine choosing not to reply to letters written in Belfast can be speculated upon, and may possibly include: the fact that generating a paper-trail of communication with a relative stranger carries risks in an area experiencing ongoing conflict, cultural differences resulting in the aims and objectives of the research becoming lost in translation, or perhaps a frustration with western researchers apparent fetish (as alluded to above) for conducting research in war-torn regions that ultimately generates few tangible results on the ground.

One further issue to consider before embarking on fieldwork in conflicted regions is the timing of the research itself. A number of colleagues and friends expressed surprise at my decision to embark on research at a time when neighbouring Arab countries were experiencing a period of uncertainty amidst popular revolution. With hindsight it is easy to validate my decision, particularly given the fact that the Arab Uprisings had little residual impact on the Palestinian population in the West Bank other than to impact positively on the Nakba commemorations in 2011, the events which I was in the field to observe and research. Nevertheless, the timing of the fieldwork should be carefully considered given that it could potentially put the lives of the researcher or participants at danger, particularly if there has been an escalation in violence.

\footnotetext{
${ }^{1}$ I was acutely aware of other researchers working in the region having their data confiscated when crossing through the many checkpoints in the region
} 
Finally, in helping to smooth my regular transition through the many checkpoints into and out of the West Bank I ensured that I carried on my person at all times a written letter of authority from my home university verifying my reasons for being in the field. The professional appearance of the letter helped to validate my position as a legitimate researcher, rather than curious onlooker or voyeuristic tourist, thus serving a similar purpose to the explanatory note.

\section{Specific challenges in the field}

\section{a) Physical Access}

One of the first major challenges I had to overcome when arriving in the field was gaining physical access to the West Bank, given the difficulties associated with entering Palestine. As an area under occupation, entrance to and from the West Bank is rigorously controlled by an ever expanding matrix of Israeli controlled military checkpoints. The complex and ever-evolving political situation meant that careful consideration had to be given to the information I was prepared to share with Israeli authorities upon my arrival in Tel Aviv Ben Gurion airport. Whereas often we speak of access primarily in terms of meeting and locating potential respondents for our work, it can simply be the case that access is taken in its literal sense, namely gaining entrance to the very area of land itself (Radsch, 2009). The potential security risks, the threat of expulsion if caught being deceitful, and the fear involved in travelling back and forth through the various checkpoints established in the area had to be measured against the ultimate aims of the research: to enter the West Bank and carry out a prolonged period of research with Palestinian respondents.

Building rapport and trust with those whom you wish to engage with can be a challenging proposition, particularly when those taking part in the research are subject to an ongoing occupation and experience the attendant difficulties of living under constant surveillance. It is perhaps not surprising then that a significant amount of time was spent on ensuring personal legitimacy amongst those whom I wanted to interview. By taking part in a wide range of additional social activities with groups and individuals whom I wished to interview, including attending film and cinema evenings, lectures and workshops, and engaging with youth groups working in the region, it was possible to develop close, personal relationships with research participants which in turn aided in generating a rigorous and verifiable data set. The casual exchanges I took part in also included being seen at a range of other Palestinian remembrance events other than the Nakba (the focus of the research).

\section{b) Ethical and other practical considerations}

As would be reasonably expected a number of ethical issues arose that required constant reassessment when in the field. Some ethical concerns centred upon a number of violent incidents that occurred during my time in Palestine, which in turn resulted in personal apprehension, fear and anxiety. Given that my work involved observing Palestinian public demonstrations and large gatherings; it was inevitable that I encountered violent counter protests and Israeli crowd dispersal techniques. Exposure to potent tear 
gas, "skunk" water, plastic ball-bearings, and on occasion live ammunition was a common occurrence which required a constant reassessment of my personal safety, and ultimately my presence in the field. Although I retained control over my personal involvement at these public events, insomuch as I could leave the scene at any time should the threats to my personal well-being become apparent, seemingly arbitrary acts of violence, including the bombing of a bus station in Jerusalem ( $23^{\text {rd }}$ March 2011) during my time living in the city caused me to call into question my reasons for being involved in fieldwork of this nature.

Given the spatial constraints in this paper, other challenges I faced can only be mentioned briefly, many of which are similar to those shared by Moffett. The difficulties associated with unreliable internal transport in conflicted regions can often mean that journeys take much longer than the distance travelled would suggest. This in turn can result in physical exhaustion as well as a need to ensure that meetings are organised with a certain degree of flexibility. On a number of occasions meetings that were scheduled to take place in the morning were cancelled or postponed until the late afternoon or evening due to a breakdown in transport or the sporadic closure of an Israeli controlled checkpoint.

A further challenge associated with any prolonged period of fieldwork is that associated with loneliness in working far from the comfort support networks of friends and family at home. In the beginning I felt extremely isolated and alone living in an area with which I was not familiar and in a place where I had no friendship networks established. Therefore, in many ways fieldwork requires great personal resolve, a degree of stamina, and perseverance.

When the fieldwork takes place against the backdrop of on-going conflict, issues concerning the management of personal safety and security take on even greater significance. This constant preoccupation with ensuring personal safety and well-being can almost be as arduous and mentally exhausting as the fieldwork itself, and as such adequate rest and recuperation should be factored into the data collection timeframe. As in Moffett's experience, I too meticulously maintained a set of research diaries, a process which provided the opportunity to reflect on the ongoing challenges impacting upon my ability to successfully achieve the aims of the research. As a useful resource in the fieldworker's toolkit, diaries can act, 'as a repository for rational thought processing and writing... [and can become] a cathartic tool used to manage and overcome potentially negative feelings' (Browne, 2013: 428). These diaries became useful means of self-reflection and greatly enhanced my ability to rationalise my presence in the field and at public events which often deteriorated into serious violence. In overcoming feelings of loneliness and isolation I involved myself proactively in the social activities of the ever expanding ex-pat community in Jerusalem and have retained close friendships in the city since departing in 2012.

\section{Discussion}

Field research can be insightful, exciting and enriching, yet it can take a toll on the researcher, being stressful, lonely and, at times, dangerous. It requires the researcher to be familiar with their fieldwork 
surroundings and ultimately be responsible for their actions whilst in it. In reflecting on the issues shared above, it is perhaps useful to divide the challenges into three areas, those that arise before, during, and after the period of fieldwork has taken place.

\section{Pre-fieldwork}

Both sets of experiences documented above show that planning and timing were key concerns. Gaining the confidence in conducting field research for the first time was greatly aided by prior travel experience in the country. Advance fieldwork trips helped demystify the region and ensured a smooth transition when we ultimately came to carrying out our research. Working in conflict and transitional societies requires a measure of personal physical and psychological resilience; as such, reflecting on the potential impact of the research on the researcher should be carefully considered before making any decision to enter the field. Regrettably, the psychological impact of research in conflict regions is rarely discussed in the final thesis, being shoehorned into an already overflowing methodology section. The reality is the psychological toll of research in conflicted or transitional fieldwork settings impacts on every stage of the research process and a greater appreciation of the challenges one would reasonably expect to face could help to better prepare those hoping to engage in this form of qualitative fieldwork.

In addition, there were stark differences in ethical requirements depending upon the school in which the research was being conducted. It is perhaps unsurprising that those schools or departments with a greater focus on research methods assessed the research proposals of early career researchers with more scrutiny than others. Similarly, the training offered at a university level is limited despite the expanding network of seasoned researchers who have experience of working in other conflicted or transitional regions. In combating these shortfalls, Browne along with colleagues from other departments in his university took it upon themselves to organise an inter-disciplinary qualitative field research network amongst doctoral candidates in the university in order to bridge this gap and to offer mutual support for early career researchers engaging in similar challenging fieldwork. The knowledge exchange this created revealed the diverse nature of fieldwork that is ongoing in universities and helped to combat a culture of silence that appeared to exist. It is hoped that this network will continue in the future as well as in other universities, complimented with a greater emphasis on university-wide training and practical support for early career researchers in advance of and when returning from a period of challenging conflict-related fieldwork.

\section{During fieldwork}

A common shared challenge during fieldwork was the difficulty in accessing participants and the generation of trust. Often trust was gained through a combination of personality, perseverance and luck. Rarely do we read of the additional steps which researchers should reasonably expect to engage in when working for a prolonged period of time in the field, yet arguably it is these ad hoc, bespoke activities, whether it be engaging in and respecting local customs or taking part in unfamiliar social events, that are of crucial importance in helping to generate a rapport with those targeted as potential research 
participants. These additional activities are often as time-consuming as the research itself and as a result should be carefully considered when drafting a timeline for the fieldwork.

As noted above, the barriers faced in terms of negotiating access to our respective places of work were considerable. At times it was necessary to conceal our intentions from those in positions of power, (including border guards, state officials) whilst retaining our transparency with potential research participants. There is therefore a fine line to be walked, with careful consideration given to whether to be entirely clear, transparent and honest about your stated research aims, even if it will result in a restriction placed upon your ability to move freely in the region, or deciding to adopt a more discreet stance

\section{Post-fieldwork}

Perhaps one of the biggest challenges to overcome when working in conflict or transitional contexts, with victimised or marginalised communities, is assuaging a reluctance to engage in what many view as a one way process of knowledge extraction and exploitation, whereby local knowledge is removed to benefit international researchers. This approach reduces, at times harrowing personal narratives, to 'knowledge' or 'information'. Researchers are often criticised for their positions in the field particularly when they come from distant and sanitised university settings. This was an issue of concern for both authors who have strived to maintain relationships in both settings despite geographical distance.

One should carefully consider post-fieldwork commitments, and appreciate that whilst at times challenging and arduous, fieldwork is an inherently privileged position. Personal testimonies shared by research participants should be gathered with respect and with clear and unambiguous guarantees on how the views will be shared. In Uganda, Moffett found that the offering of knowledge and explanation of ongoing activity at the ICC and domestic proceedings was a welcome means of ensuring research participants were well informed on current issues as they were unfolding. This practice also helped to feed grassroots approaches to transitional justice issues by informing those most affected. Both authors disseminated their findings in a wide array of means, through both print and online media outlets, gallery exhibitions at home, and online internet blogging from the field. In addition, both authors have made commitments to return to the field to disseminate findings to research participants with Browne returning annually to attend the continuously developing Nakba commemorations in Ramallah and to retain close contacts with research participants. Returning to disseminate research findings, sharing the research findings as widely as possible through a range of mediums, and conducting teaching seminars for key stakeholders on contemporary issues, are all ways of ensuring that those inherently personal stories and narratives shared during the research process are not solely confined to the library shelves.

It is crucial for early career and more established researchers to engage in continued critical reflection on the impact that research is having on the environment. In addition, researchers should engage with research participants at every stage of the research process, consistent with a human rights 
based approach that ensures respect for research participants' dignity, privacy and personal inviolability. This is particularly true with regards to the positionality of the researcher in the field as a perceived 'expert' and expectations of them by respondents and the responsibility that comes with such research (Darling, 2014). Both authors agree that knowledge exchange is an important component that should be built in to ethics committees' assessment of fieldwork proposals, which will hopefully help to safeguard both, vulnerable research participants and researchers proposing future fieldwork research in conflicted and/or transitional settings. Field research thus becomes a collective and mutual effort, which is not 'owned' by the researcher.

\section{Conclusion}

As Shaffir et al (1991: 1) have previously suggested, 'Fieldwork must certainly rank with the more disagreeable activities that humanity has fashioned for itself. It is usually inconvenient, to say the least, sometimes physically uncomfortable, frequently embarrassing, and to a degree, always tense'.While field research can indeed be daunting, it is also an extremely rewarding experience that enriches understanding and insight into the complexities of countries in conflict and transition. It is a privilege to conduct field research, but as noted above it comes with responsibilities. The experiences we have shared above highlight that issues relating to: timing, planning, being ethically vigilant, respecting research participants, and ensuring that knowledge is appropriately exchanged, are of critical concern. Our perspectives, while consistent with contemporary social science research experiences, is by no means comprehensive, however, we share them openly in the hope that it will encourage other transitional justice and human rights scholars to reflect on their own field research and the lessons that can be learned from our first steps into the field. 


\section{Bibliography}

Berman, R.C., and Tyyskä, V., A Critical Reflection on the Use of Translators/Interpreters in a Qualitative Cross- Language Research Project, International Journal of Qualitative Methods 10(1) (2010) 178-190.

Browne, B., 'Recording the Personal: The Benefits in Maintaining Research Diaries for Documenting the Emotional and Practical Challenges of Fieldwork in Unfamiliar Settings', International Journal of Qualitative Methods, 12, (2013) 420- 435.

Burgess, R. G., (ed.) Field Research: A Source Book and Field Manual, (Allen and Unwin 1982).

Darling, J, Emotions, encounters and expectations: the uncertain ethics of 'the field', Journal of Human Rights Practice (under review).

Jacobsen, K. and Landau, L., 'Researching Refugees: Some Methodological and Ethical Considerations in Social Science and Forced Migration', New Issues in Refugee Research, Working Paper No.90, Geneva: UNHCR Evaluation and Policy Analysis Unit (2003).

King, J. C., 'Demystifying field research', in C. L. Sriram, J. C. King, J. A. Mertus, O. M. Ortega, \& J. Herman (Eds) Surviving Field Research: Working in violent and difficult situations, (Routledge 2009).

Kovats-Bernat, J. C., 'Negotiating Dangerous Fields: Pragmatic Strategies for Fieldwork amid Violence and Terror', American Anthropologist, 104(1)(2002), 208- 222.

Knox, C., 'Establishing research legitimacy in the contested political ground of contemporary Northern Ireland', Qualitative Research, 1(2) (2001), 205- 222.

McCann, L., Pearlman, L.A, 'Vicarious traumatization: A framework for understanding the psychological effects of working with victims', Journal of Traumatic Stress, January 1990, 3(1) 131-149

Moffett, L., Justice for Victims before the International Criminal Court, Routledge (2014).

Nordstrom, C., and Robben, A. C. G. M., Fieldwork Under Fire: Contemporary Studies of Violence and Survival, (University of California Press 1995)

Pittaway, E., Bartolomei L., and Hugman, R., "Stop Stealing Our Stories': The Ethics of Research with Vulnerable Groups', Journal of Human Rights Practice (2010) 2(2), 229-251.

Radsch, C., 'From cell phones to coffee; Issues of access in Egypt and Lebanon', in C. L. Sriram, J.C. King, J. A. Mertus, O. Martin-Ortega, and J. Herman, (eds.) Surviving Field Research: Working in violent and difficult situations, (Routledge 2009).

Romano, D., 'Conducting research in the Middle East's conflict zones', Political Science and Politics 3 (2006) 439-441. 
Shaffir, W. B., and R. A. Stebbins, (eds). Experiencing Fieldwork: An Inside View of Qualitative Research, (Sage Publications 1991).

Sluka, J. A., 'Participant observation in violent social contexts', Human Organisation, 49(20) (1990), 114-126.

Temple, B and A. Young, 'Qualitative Research and Translation Dilemmas', Qualitative Research 4(1) (2004) 161

Wood, E.J., 'The Ethical Challenges of Field Research in Conflict Zones', Qualitative Sociology 29(3) 373-386 